\title{
The Lebanese mutation as an important cause of familial hypercholesterolemia in Brazil
}

\section{F.L. Alberto, M.S. Figueiredo, \\ M.A. Zago, A.G. Araújo and J.E. Dos-Santos}

\author{
Departamento de Clínica M édica, \\ Faculdade de Medicina de Ribeirão Preto, \\ Universidade de São Paulo, Ribeirão Preto, SP, Brasil
}

\section{Correspondence \\ J.E. Dos-Santos \\ Departamento de Clínica Médica \\ FMRP, USP \\ 14049-900 Ribeirão Preto, SP \\ Brasil \\ Fax: + 55-16-633-1144 \\ E-mail: jedsanto@ fmrp.usp.br}

Research supported by FAPESP, CNPq and FINEP.

Received August 13, 1998

Accepted March 17, 1999

\section{Abstract}

Familial hypercholesterolemia (FH) is a common autosomal disorder that affects about one in 500 individuals in most Western populations and is caused by a defect in the low-density-lipoprotein receptor (LDLr) gene. In this report we determined the molecular basis of FH in 59 patients from 31 unrelated Brazilian families. All patients were screened for the Lebanese mutation, gross abnormalities of the LDLr gene, and the point mutation in the codon 3500 of the apolipoprotein B-100 gene. None of the 59 patients presented the apoB-3500 mutation, suggesting that familial defective ApoB-100 (FDB) is not a major cause of inherited hypercholesterolemia in Brazil. A novel 4-kb deletion in the LDLr gene, spanning from intron 12 to intron 14, was characterized in one family. Both 5' and $3^{\prime}$ breakpoint regions were located within Alu repetitive sequences, which are probably involved in the crossing over that generated this rearrangement. The Lebanese mutation was detected in 9 of the 31 families, always associated with Arab ancestry. Two different LDLr gene haplotypes were demonstrated in association with the Lebanese mutation. Our results suggest the importance of the Lebanese mutation as a cause of FH in Brazil and by analogy the same feature may be expected in other countries with a large Arab population, such as North American and Western European countries.

\section{Introduction}

Familial hypercholesterolemia (FH) is a common autosomal disorder caused by a defect in the low-density-lipoprotein receptor (LDLr) gene. It affects about one in 500 individuals in most Western populations and is characterized by elevated serum LDL cholesterol levels, tendon xanthomas and premature coronary artery disease (1). The analysis of the LDLr gene in FH patients has led to the identification of more than 150 different mutations which include deletions, point mutations and insertions (2). Probably due to the founder effect, specific mutations are present at higher frequencies in certain populations, such as the Afrikaner- 1 and -2 alleles in the Afrikaner population of South Africa, the French-Canadian allele in the FrenchCanadian population, the Helsinki allele in the Finnish population and the Lebanese allele in Middle East populations (3). 
The Brazilian population is composed of various ethnic groups, mainly Caucasians of European descent, Blacks, Amerindians, and, to a much lesser extent, Asians and Arabs (4). In a preliminary study we identified the Lebanese allele in 5 out of 10 unselected Brazilian families with $\mathrm{FH}$, always in association with Arab ancestry, suggesting an important contribution of this ethnic group to the prevalence of FH in Brazil (5).

In the present study, we extended our search for the Lebanese allele and screened for other structural abnormalities of the LDLr gene in Brazilian FH patients. In addition, the LDLr gene haplotypes associated with FH were determined in selected cases. Finally, we also examined the role of the point mutation in the codon 3500 of the apolipoprotein B-100 gene as another cause of hypercholesterolemia in these patients.

\section{Patients and Methods}

\section{Patients}

We studied $59 \mathrm{FH}$ patients from 31 unrelated and unselected Brazilian families. Ten patients were previously described in a preliminary search for the Lebanese mutation (5). Most of these patients are regularly followed at the University Hospital in Ribeirão Preto; blood samples from 6 families were generously provided by E. Quintão (School of Medicine, University of São Paulo, Brazil) and included patients from the States of Minas Gerais and Bahia. Their ethnicity was assumed based on the description of the origins of their relatives. The diagnosis of FH was based on the following criteria: total plasma cholesterol and LDL cholesterol above the 95th percentile for age and sex, triglyceride levels below $400 \mathrm{mg} \%$, and autosomal inheritance (1). Total cholesterol (6) and triacylglycerol (7) concentrations were measured with a Cobas-Bio centrifugal analyzer (Roche Diagnostic, Basel, Switzerland) using enzymatic kits (Roche Diagnos- tic) and control sera. LDL cholesterol was calculated using the Friedwald equation (8). In Table 1, we summarize the clinical features of the families investigated here.

\section{DNA analysis}

High molecular weight genomic DNA was isolated from peripheral blood leukocytes by phenol/chloroform extraction (9).

Southern blotting/hybridization assay. Five to $7 \mu \mathrm{g}$ of DNA were digested with $X b a \mathrm{I}, \mathrm{Kp} n \mathrm{I}$ and BamHI restriction endonucleases, separated on $1 \%$ agarose gels, and blotted onto nylon membranes (GeneScreen Plus, DuPont, Wilmington, DE) (9). The filters were hybridized to fragments of human LDLr cDNA (obtained from clone pLDLR3, purchased from American Type Culture Collection, Rockville, MD) at $42^{\circ} \mathrm{C}$ for $16-48 \mathrm{~h}$ and washed at $65^{\circ} \mathrm{C}$ for $60 \mathrm{~min}$. The probes were labelled with $\left[\alpha_{-}{ }^{32} \mathrm{P}\right] \mathrm{dCTP}$ by random oligonucleotide priming (9). The membranes were exposed to X-ray films (XOmat AR, Kodak) with intensifying screens for 1 to 7 days. In order to characterize the deletion observed in family 2, BamHI-digested DNA samples were hybridized to the oligonucleotides A (5'-ATGACAGGGGTCT CCTATACCAGGAGAAGGTGTTGGA GTG-3') and B (5'-CGATCCGACGTCAC CGGTGGGTCCTCAGTAGGTGGCAGTC CG-3') as specific probes for exons 13 and 15, respectively. Hybridization conditions were as described above, except that the filters were washed at $55^{\circ} \mathrm{C}$ for $30 \mathrm{~min}$.

Haplotype analysis. For LDLr gene haplotype determination, the following polymorphic sites were investigated: $S t u \mathrm{I}$ (exon 8), AvaII (exon 13), ApaLI (intron 15), PvuII (intron 15) and NcoI (exon 18) (10). The $A p a \mathrm{LI}, P v u \mathrm{II}$, and $N c o \mathrm{I}$ polymorphisms were analyzed by Southern blotting (as described above) using a 2.1-kb Bam HI fragment (exons 10-18) of the LDLr cDNA as probe. StuI and $A v a$ II polymorphisms were analyzed by PCR amplification (see below) of a DNA 
segment containing the polymorphic site followed by digestion with the appropriate enzyme. When necessary, non-affected members of the families were also studied in order to identify the LDLr gene haplotype in association with the abnormal gene.

Polymerase chain reaction (PCR). The Lebanese allele was detected by the selective amplification of exon 14 of the LDLr gene followed by HinfI digestion, as previously described (5). To characterize the de- letion identified in family 2 , a segment containing the deletion breakpoints was amplified using the primers P1 (5'-CTTGGAGGA TGAAAAGGCTGG-3') and P2 (5'-TGACC TTTAGCCTGACGGTGGATG-3'), which are complementary to exons 12 and 15, respectively. The polymorphic site AvaII was investigated using the primers P3 (5'-CTTCC TTCCTTGCTGCCTGT-3') and P4 (5'-TG TGAGGCAGCTCCTCATGT-3'). The primers P5 (5'-CCAAGCCTCTTTCTCTCTCTC

Table 1 - Clinical and laboratory features, ethnic background and detection of the Lebanese mutation in the patients included in this study.

Age (in years) at diagnosis; N: number of analyzed individuals per family; Tc: total cholesterol; LDL-c: lowdensity lipoprotein cholesterol. TX: tendon xanthomata; AMI: acute myocardial infarction; UA: unstable angina. Families 1 to 10 were reported previously (Ref. 5); + and - denote the presence (always in heterozygosity) or absence of the Lebanese mutation; a one patient with clinical and laboratory data compatible with homozygous $\mathrm{FH}$, and all other patients were diagnosed as heterozygotes for $\mathrm{FH}$. Cholesterol $\mathrm{mg} / \mathrm{dl}=\mathrm{mmol} / \mathrm{l}$ x 38.6. Triglyceride $\mathrm{mg} / \mathrm{dl}=\mathrm{mmol} / \mathrm{l} \times 88.5$.

\begin{tabular}{|c|c|c|c|c|c|c|c|}
\hline $\begin{array}{l}\text { Family } \\
\text { number }\end{array}$ & $\mathrm{N}$ & $\begin{array}{c}\text { Age } \\
\text { (years) }\end{array}$ & $\begin{array}{c}\mathrm{Tc} \\
(\mathrm{mmol} / \mathrm{l})\end{array}$ & $\begin{array}{l}\text { LDL-C } \\
(\mathrm{mmol} / \mathrm{l})\end{array}$ & $\begin{array}{c}\text { Clinical } \\
\text { features }\end{array}$ & $\begin{array}{l}\text { Ethnic } \\
\text { origin }\end{array}$ & Lebanese mutation \\
\hline 1 & 3 & $36-40$ & 8.4-10.8 & $6.5-8.7$ & $\mathrm{TX}$ & Lebanese & + \\
\hline 2 & 1 & 64 & 13.7 & 11.2 & AMI & Italian & - \\
\hline 3 & 1 & 38 & 8.5 & 6.9 & AMI & Lebanese & + \\
\hline 4 & 2 & $20-46$ & 9.6-10.1 & 7.4-8.6 & AMI/TX & Lebanese & + \\
\hline 5 & 1 & 57 & 7.4 & 5.5 & AMI & Portuguese & - \\
\hline 6 & 2 & $50-52$ & 7.3-8.2 & 5.4-6.3 & none & Portuguese & - \\
\hline 7 & 4 & $45-69$ & $7.4-9.3$ & $5.7-7.5$ & AMI & Italian & - \\
\hline 8 & 1 & 65 & 7.1 & 5.2 & AMI & Italian & - \\
\hline 9 & 2 & $46-58$ & $8.5-9.6$ & $7.5-8.8$ & AMI & Syrian & + \\
\hline 10 & 4 & $34-54$ & $6.9-15.8$ & $5.1-14.1$ & TX/AMI & Lebanese $^{a}$ & + \\
\hline 11 & 1 & 47 & 6.9 & 5.8 & none & Portuguese & - \\
\hline 12 & 1 & 30 & 12.8 & 10.2 & $\mathrm{TX}$ & Portuguese & - \\
\hline 13 & 1 & 55 & 9.0 & 7.1 & none & Portuguese & - \\
\hline 14 & 1 & 25 & 12.1 & 10.4 & none & Portuguese & - \\
\hline 15 & 1 & 14 & 5.8 & 4.9 & none & Portuguese & - \\
\hline 16 & 1 & 28 & 6.2 & 5.3 & none & Portuguese & - \\
\hline 17 & 7 & 14-67 & $6.7-9.4$ & $5.5-7.9$ & none & Spanish & - \\
\hline 18 & 1 & 42 & 8.3 & 7.2 & AMI & Lebanese & + \\
\hline 19 & 2 & $6-38$ & $6.8-7.2$ & 5.8-6.1 & none & Lebanese & + \\
\hline 20 & 1 & 49 & 7.5 & 6.8 & AMI & Lebanese & + \\
\hline 21 & 1 & 46 & 6.3 & 4.0 & none & Italian & - \\
\hline 22 & 1 & 68 & 7.6 & 6.2 & UA & Lebanese & - \\
\hline 23 & 1 & 38 & 10.1 & 7.6 & none & Italian & - \\
\hline 24 & 2 & 48 & $9.3-10.8$ & $7.2-8.0$ & none & Italian & - \\
\hline 25 & 1 & 49 & 5.9 & 4.6 & none & Portuguese & - \\
\hline 26 & 1 & 9 & 7.6 & 5.0 & none & Portuguese & - \\
\hline 27 & 1 & 4 & 7.0 & 4.6 & none & Portuguese & - \\
\hline 28 & 4 & $13-57$ & $5.1-6.9$ & $3.5-5.3$ & TX/UA & Italian & - \\
\hline 29 & 3 & $9-57$ & 7.0-10.8 & $5.5-8.5$ & none & Lebanese & + \\
\hline 30 & 3 & $13-46$ & 5.6-13.6 & $3.7-12.0$ & none & Portuguese & - \\
\hline 31 & 1 & 59 & 8.8 & 6.0 & none & Italian & - \\
\hline
\end{tabular}


Figure 1 - Southern blot/hybridization analysis of the mutant gene detected in family 2. A, BamHI-digested DNA samples hybridized to an LDLr CDNA DNA samples digested with BamHI/Kpnl and Xbal, hybridized to the same probe as in $A$. C, BamHI-digested DNA samples hybridized to specific probes for exons 13 and 15 . The asterisks indicate abnormal bands; the size of the bands (in $\mathrm{kb})$ are indicated on the right; the exons contained within each segment are indicated in parentheses. P, Patient; C, control; N, normal band; $\mathrm{D}$, deletion mutant. probe spanning exons 10-18. B,

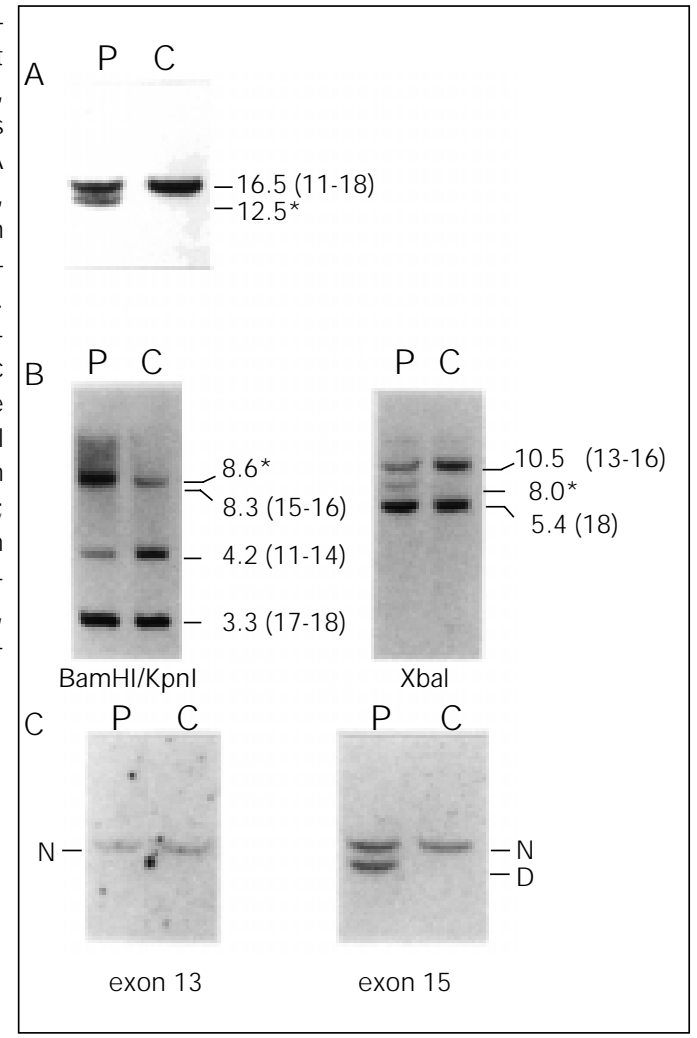

Figure 2 - PCR amplification across the deletion junctions of the mutation characterized in family 2. Top, PCR products separated on $1 \%$ agarose gel. Lane $M$, molecular weight marker; lanes 1 and 2, two affected members of the family; lane 3 , unaffected control sample. Bottom, Restriction map of the deletion mutant (the normal map is shown for comparison). Arrows, Alu sequences; horizontal bars, deletion breakpoint regions; solid vertical bars, exons; horizontal line, introns; S, Sphl; P, Pstl; E, EcoRV; X, Xbal.

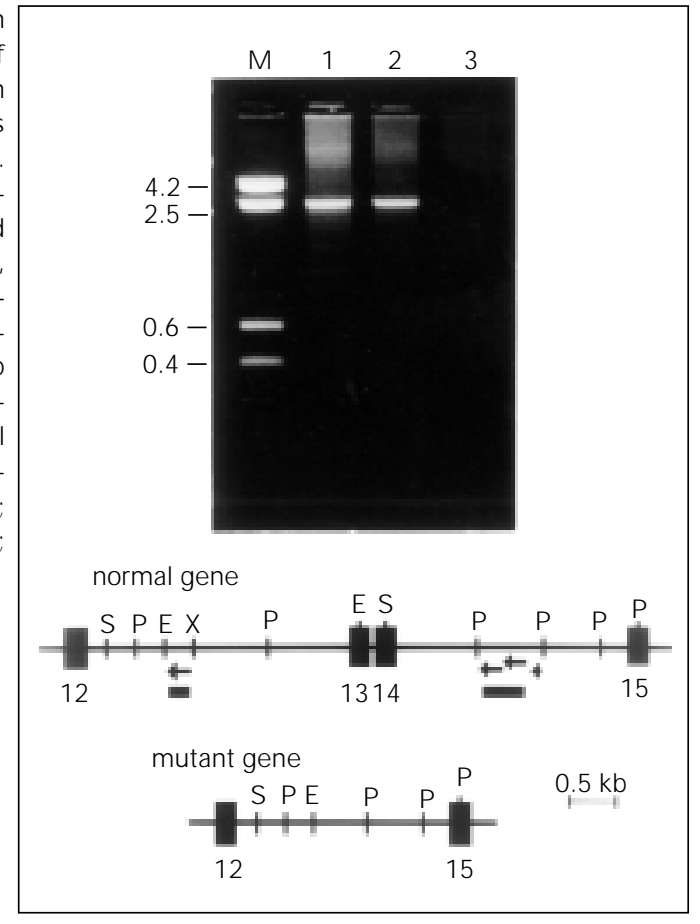

TTCCA-3') and P6 (5'-CCACCCGCCGCCT TCCCGTGCT-3') were used to analyze the polymorphic site $S t u$ I. All PCR experiments were performed using a $50-\mu 1$ total reaction volume containing $100 \mathrm{ng}$ of genomic DNA, $10 \mathrm{mM}$ Tris- $\mathrm{HCl}, 1.5 \mathrm{mM} \mathrm{MgCl} 2,0.01 \%$ BSA, $200 \mu \mathrm{M}$ of each dNTP, $0.25 \mu \mathrm{M}$ of each primer, and $1 \mathrm{U}$ of Taq DNA polymerase; 35 cycles of amplification were carried out (typically, $94^{\circ} \mathrm{C}$ for $30 \mathrm{~s}, 55^{\circ} \mathrm{C}$ for 50 $\mathrm{s}$ and $72^{\circ} \mathrm{C}$ for $1 \mathrm{~min}$ ) in a Perkin Elmer Cetus thermal cycler (Norwalk, CT). All oligonucleotides were synthesized with an Applied Biosystems 391 oligonucleotide synthesizer, based on the cDNA sequence previously reported (11).

Detection of apoB-3500 mutation. To detect the apoB-3500 mutation, a single primer-template mismatch approach with subsequent digestion with the enzyme $M s p$ I was performed as described (12).

\section{Results}

For only one of the 31 families included in this study was it possible to identify a gross deletion as the molecular defect associated with FH. DNA samples from the affected member of family 2 (Table 1 ) digested with BamHI and hybridized to a cDNA probe that covers exons 10-18 revealed an abnormal band of $12.5 \mathrm{~kb}$ in addition to a reduction in intensity of the expected 16.5$\mathrm{kb}$ band (Figure 1A). Xbal-digested DNA hybridized to this probe revealed an abnormal band of $8.0 \mathrm{~kb}$ and a reduction in intensity of the normal $10.5-\mathrm{kb}$ band, which contains exons 13-16 (Figure 1B). BamHI/KpnI double-digested DNA hybridized to the same probe showed a reduced intensity for the normal 4.2-kb band (exons 11-14) and an abnormal band of $8.6 \mathrm{~kb}$ (Figure 1B). These results indicate the occurrence of a partial deletion of about $4 \mathrm{~kb}$ encompassing exon 14 in a heterozygous patient. By probing BamHI-digested DNA samples with oligo- 
nucleotides A (complementary to exon 13) and $\mathrm{B}$ (complementary to exon 15) we were able to locate the $5^{\prime}$ and $3^{\prime}$ deletion breakpoints within introns 12 and 14, respectively (Figure 1C). Further analysis was performed by selective amplification of the region spanning the deletion breakpoints using the primers P1 and P2 (complementary to exons 12 and 15 , respectively), which are located 2.5 $\mathrm{kb}$ apart from each other in the mutant gene (Figure 2). These primers are separated by a segment of $6.5 \mathrm{~kb}$ in the wild type gene, precluding its amplification under the conditions described here (lane 3, Figure 2). The 2.5 -kb amplified mutant segment was then subjected to a series of digestions with the enzymes XbaI, PstI, EcoRV, and SphI, to provide a restriction map (Figure 2). This strategy enabled us to determine both $5^{\prime}$ and 3 ' breakpoint regions (within $\pm 900 \mathrm{bp}$ of certainty), both within Alu repetitive sequences (Figure 2).

The Lebanese mutation was detected in 9 of the 31 families, always as a heterozygote and in association with Arab ancestry (Table 1). Haplotype analysis revealed a common single haplotype in association with the Lebanese mutation in 8 families: +++-- (+ and indicate the presence and absence of the sites StuI, AvaII, ApaLI, PvuII, and NcoI, respectively). This particular haplotype has been reported in association with the Lebanese mutation in all of the few patients that have been evaluated for this purpose (10). In one family (family 20 , Table 1 ) a distinct haplotype (+----) was observed. None of the patients presented the apoB-3500 mutation (data not shown).

\section{Discussion}

The molecular basis of FH in the Brazilian population is poorly characterized. In the present study, we also searched for the mutation in the codon 3500 of the apolipoprotein B-100 gene because the two diseases, FH and familial defective apolipoprotein B-100 (FDB), have similar clinical features and prevalence $(12,13)$. None of the 59 patients investigated here presented the apoB-3500 mutation. These results agree with the study of Schuster et al. (14) in a German population, who found only $3 \%$ of FDB patients among those previously diagnosed as $\mathrm{FH}$. Therefore, we assume that the vast majority, if not all, of our patients are in fact affected by FH.

Gross structural rearrangements in the LDLr gene represent a minority of the FH cases, a feature that is also observed for other human genetic diseases, such as Lesch Nyhan syndrome, hemophilias A and B, and antithrombin III deficiency (15-17). Today, more than 30 different deletions have been described in the LDLr gene (17). In the present study, we demonstrated a 4-kb deletion involving both exons 13 and 14 of the LDLrgene. A similar mutation was described by Horsthemke et al. (18), although in that case a different restriction map was observed in the deletion $5^{\prime}$ breakpoint region. Nevertheless, in both cases the $5^{\prime}$ and $3^{\prime}$ breakpoint regions are located within Alu-repetitive sequences having the same orientation (1719). Therefore, it is reasonable to assume an unequal crossing-over involving these repetitive sequences as the likely mechanism for these rearrangements. Alu-rich sequences are found throughout the LDLr gene (introns $1-8,12-17$, and 3 ' untranslated region) and are associated both with deletions and insertions of the LDLr gene $(15,17,18,20,21)$. Indeed, some investigators suggest the presence of recombinational hotspots in the LDLr gene involving Alu elements (17). The biological role of Alu sequences is not known, though they constitute about $6 \%$ of the human genome (17). Moreover, recombination involving the repetitive family of Alu sequences is the postulated mechanism for gene rearrangements in several other human diseases such as non-insulin-dependent dia- 
betes mellitus (22), lipoprotein lipase deficiency $(23,24)$, C3 deficiency (25), some types of familial thrombophilia (16), Lesch Nyhan syndrome (26), adenosine deaminase deficiency (27), and others (25).

In a previous paper we pointed out the possible contribution of the Lebanese allele to the prevalence of $\mathrm{FH}$ in Brazil, far in excess of the proportion of individuals of Arab ancestry in the Brazilian population (5). Now we confirm that result by the analysis of a larger number of FH families. We predict that this observation will contribute to the early diagnosis of $\mathrm{FH}$ in cases presumed to be of Arab ancestry. Indeed, antenatal diagnosis could be performed in selected cases.

Arab ancestry was present in all patients bearing the Lebanese mutation in our population. Haplotype analysis revealed the same single haplotype in 8 of $9 \mathrm{FH}$ families bearing the Lebanese mutation: ++--. This particular haplotype has been previously described in association with the Lebanese mutation (10). Surprisingly, a different haplotype was determined in one family: +----, which shows different results for polymorphic sites located at 5' (AvaII) and 3' (ApaLI) of the Lebanese mutation. The occurrence of two different haplotypes in association with the same mutation may be explained by several genetic mechanisms: a) modification of the ancestor haplotype by at least two recombination events, b) gene conversion, and c) occurrence of a recurrent mutation in chromosomes bearing different haplotypes (28). Extensive haplotype studies in FH patients from Middle East populations would be necessary to elucidate this point.

The Lebanese mutation was detected in approximately $30 \%$ of our patients. Our series contained $59 \mathrm{FH}$ individuals from 31 families. This is the largest series of patients with FH reported in the country and includes patients mainly from the Southern region of
Brazil. If there are more than 50 different single point mutations, which can lead to familial hypercholesterolemia, the fact that almost $30 \%$ of the mutations detected in our population are Lebanese indicates the importance of the Lebanese mutation in the population studied. Thus, it seems also reasonable to conclude that the Lebanese mutation is an important cause of FH in Brazil. This finding was originally unexpected because of the negligible contribution of Arabs to the composition of the Brazilian population (4). However, we should consider that, although constituting a small group, the Arabs present a much higher prevalence of $\mathrm{FH}$ than the groups that primarily compose the Brazilian population (Caucasians of European descent, Blacks and Amerindians), which explains our observation. It is also tempting to speculate that the same feature may be occurring in other countries with mixed populations (and an even larger Arab population), such as North American and Western European countries (e.g., France, Germany, and England). Supporting this assumption, Cavanaugh et al. (29) reported the detection of the Lebanese mutation in 2 out of $15(13 \%)$ Australian patients with FH, always in association with Arab descent. The authors interpreted this finding as the result of the recent immigration of Arabs to the Australian continent. To our knowledge, no other study was conducted to search for the Lebanese mutation in FH patients outside the Middle East. It is therefore recommended that this approach be extended to other countries.

\section{Acknowledgments}

The authors are grateful to Dr. E. Quintão for sending us blood samples from six affected families, and to M.H. Tavella, M.H.S. Scaffo, and J. Komoto for their expert technical assistance. 


\section{References}

1. Goldstein J L \& Brown MS (1989). Familial hypercholesterolaemia. In: Scriver CR, Beaudet AL, Sly WS \& Valle D (Editors), The Metabolic Basis of Inherited Disease. 6th edn. McGraw-Hill, New York, 12151250.

2. Hobbs HH, Brown MS \& Goldstein J L (1992). Molecular genetics of the LDL receptor gene in familial hypercholesterolemia. Human Mutation, 1: 445-466.

3. Hobbs HH, Russel DW, Brown MS \& Goldstein J L (1990). The LDL receptor locus in familial hypercholesterolaemia: molecular analysis of a membrane protein. Annual Review of Genetics, 24: 133170.

4. Daune D (Editor) (1991). Britannica Book of the Year. Encyclopaedia Britannica, Chicago, 560-561.

5. Figueiredo MS, Santos J E, Alberto FL \& Zago MA (1992). High frequency of the Lebanese allele of the LDLr gene among Brazilian patients with familial hypercholesterolaemia. J ournal of Medical Genetics, 29: 813-815.

6. Allain CC, Poon LS, Chon CSG, Richmond U \& Fu PC (1974). Enzymatic determination of total serum cholesterol. Clinical Chemistry, 20: 470-475.

7. Fossati $P \&$ Principe L (1982). Serum triacylglycerols determined colorimetrically with an enzyme that produces hydrogen peroxide. Clinical Chemistry, 28: 20772080.

8. Friedwald W, Levy $R \&$ Fredrickson $D$ (1972). Estimation of the concentration of low-density lipoprotein cholesterol in plasma without use of the preparative ultracentrifuge. Clinical Chemistry, 18: 499502.

9. Sambrook J , Fritsch EF \& M Maniatis T (Editors) (1989). Molecular Cloning: A Laboratory Manual. 2nd edn. Cold Spring Harbor Laboratory Press, New York.

10. Berkman N, Weir BS, Pressman-Schwartz S, Ayeleth R \& Leitersdorf E (1992). Haplotype analysis at the low-density lipoprotein receptor locus: application to the study of familial hypercholesterolemia in Israel. Human Genetics, 88: 405-410.

11. Yamamoto T, Davis CG, Brown MS, Schneider WJ, Linette Casey $M$, Goldstein J L \& Russel DW (1984). The human LDL receptor: a cysteine-rich protein with multiple alu sequences in its mRNA. Cell, 39: 27-38.

12. Hansen PS, Rudiger N, Tybjaerg-Hansen
A, Faegerman D \& Gugersen N (1991). Detection of the apoB-3500 mutation (glutamine for arginine) by gene amplification and cleavage with Mspl. J ournal of Lipid Research, 32: 1229-1233.

13. Tybjaerg-Hansen $A \&$ Humphries SE (1992). Familial defective apolipoprotein B-100: a single mutation that causes hypercholesterolaemia and premature coronary artery disease. Atherosclerosis, 96: 91-107.

14. Schuster H, Rauh G, Gerl C, Keller C, Wolfram G \& Zöllner N (1991). Use of DNA haplotype analysis in diagnosis of familial hypercholesterolaemia in 31 German families. J ournal of Medical Genetics, 28 : 865-870.

15. Rüdiger NS, Hansen PS, J ørgensen $M$, Faergeman O, Bolund L \& Gregersen N (1991). Repetitive sequences involved in the recombination leading to deletion of exon 5 of the low-density-lipoprotein receptor gene in a patient with familial hypercholesterolemia. European J ournal of Biochemistry, 198: 107-111.

16. Olds RJ, Lane DA, Chowdhury V, De Stefano V, Leone G \& Thein SL (1993). Complete nucleotide sequence of the antithrombin gene: evidence for homologous recombination causing thrombophilia. Biochemistry, 32: 4216-4224.

17. Rüdiger NS, Gregersen N \& KiellandBrandt MC (1995). One short well conserved region of Alu-sequences is involved in human gene rearrangements and has homology with prokaryotic-chi. Nucleic Acids Research, 23: 256-260.

18. Horsthemke B, Beisiegel U, Dunning A, Havinga J R, Williamson R \& Humphries S (1987). Unequal crossing-over between two alu-repetitive DNA sequences in the low-density-lipoprotein-receptor gene. European J ournal of Biochemistry, 164: 77-81.

19. Miyake $Y$, Tajima $S$, Funahashi $T \&$ Yamamoto A (1989). Analysis of a recycling-impaired mutant of low density lipoprotein receptor in familial hypercholesterolemia. J ournal of Biological Chemistry, 264: 16584-16590.

20. Lehrman MA, Russel DW, Goldstein J L \& Brown MS (1987). Alu-Alu recombination deletes splice acceptor sites and produces secreted low density lipoprotein receptor in a subject with familial hypercholesterolemia. J ournal of Biological Chemistry, 262: 3354-3361.
21. Kigawa K, Kihara K, Miyake Y, Funahashi T, Yamamura T \& Yamamoto A (1993). Low-density lipoprotein receptor mutation that deletes exon 2 and 3 by Alu-Alu recombination. J ournal of Biochemistry, 113: 372-376.

22. Elbein SC (1992). Linkage disequilibrium among RFLPs at the insulin-receptor locus despite intervening Alu repeat sequences. American J ournal of Human Genetics, 51: 1103-1110.

23. Benlian P, Etienne J, Gennes J L, Noé L, Brault D, Raisonnier A, Amault F, Hamelin J , Foubert L, Cuat J C, Tse CT \& Galibert F (1995). Homozygous deletion of exon 9 causes lipoprotein lipase deficiency: possible intron-Alu recombination. J ournal of Lipid Research, 36: 356-366.

24. Chuat J C, Raisonnier A, Etienne J \& Galibert F (1992). The lipoprotein lipaseencoding human gene: sequence from intron- 6 to intron-9 and presence in intron-7 of a 40-million-year-old Alu sequence. Gene, 110: 257-261.

25. Botto $M$, Fong $K Y$, So AK, Barlow $R$, Routier R, Morley BJ \& Walport MJ (1992). Homozygous hereditary C3 deficiency due to a partial gene deletion. Proceedings of the National Academy of Sciences, USA, 89: 4957-4961.

26. Marcus $S$, Hellgren $D$, Lambert $B$, Fällström SP \& Wahlström J (1993). Duplication in the hypoxanthine phosphoribosyl-transferase gene caused by Alu-Alu recombination in a patient with Lesch Nyhan syndrome. Human Genetics, 90: 477-482.

27. Shovlin $C L$, Simmonds HA, Fairbanks LD, Deacock SJ, Hughes J MB, Lechler RI, Webster ADB, Sun XM, Webb JC\& Soutar AK (1994). Adult onset immunodeficiency caused by inherited adenosine deaminase deficiency. J ournal of Immunology, 153: 2331-2339.

28. Antonarakis $\mathrm{SE}$, Boehm CD, Sergeant GR, Theisen CE, Dover GJ \& Kazazian J r HH (1984). Origin of beta-S-globin gene in Blacks: contribution of recurrent mutation or gene conversion or both. Proceedings of the National Academy of Sciences, USA, 81: 853-856.

29. Cavanaugh J A, Easteal $S$, Simons $L \&$ Serjeanson S (1992). A rapid method for diagnosis of the Lebanese allele in the low-density lipoprotein receptor gene. Human Heredity, 42: 189-192. 